\title{
Turbidity Sensor for Bacterial Growth Measurements in Spaceflight and Simulated Micro-gravity
}

\author{
Roel van Benthem • Wubbo de Grave
}

Received: 29 February 2008 / Accepted: 18 October 2008 / Published online: 19 November 2008

(C) The Author(s) 2008. This article is published with open access at Springerlink.com

\begin{abstract}
For the BIOFILTER flight experiment a set of turbidity sensors was developed for the measurement of the growth rate of the bacteria Xanthobacter autrophicus GJ10 in a fluid medium. During the flight experiment on FOTON M2 in 2005, bacterial growth was measured revealing growth rates between $0.046-$ $0.077 \mathrm{~h}^{-1}$ in microgravity, i.e. approximately $1.5-2.5$ times slower than routinely measured under optimal laboratory conditions on earth. To increase confidence in the equipment and for comparison of the results, a ground-reference experiment was carried out in 2006, using BIOFILTER hardware mounted on a random positioning machine (RPM). The RPM performed random rotations at $0.5^{\circ} / \mathrm{min}$ (for settling compensation) and $90 \% \mathrm{~min}$ (for simulated microgravity) while the environment was controlled, accurately repeating the BIOFILTER flight temperature conditions. Despite the rotations of the RPM, a normal growth rate of $0.115 \mathrm{~h}^{-1}$ was confirmed in both cases. The operation of the turbidity sensor was verified. Biological interpretation of the measurements is however compromised due to poor mixing and other unknown physical and biological phenomena that need to be addressed for further space experiments using these kinds of systems.
\end{abstract}

R. van Benthem $(\varangle) \cdot$ W. de Grave

National Aerospace Laboratory NLR,

Amsterdam, The Netherlands

e-mail: benthem@nlr.nl

URL: www.nlr.nl

W. de Grave

e-mail: grave@nlr.nl
Keywords Turbidity sensor • Bacterial growth measurements · BIOFILTER · FOTON M2 space flight $\cdot$ Bacteriological air filter • Ground reference experiment • Random positioning machine

$\begin{array}{ll}\text { Abbreviations } \\ \text { ESA-MAP } & \begin{array}{l}\text { Molecular tools for monitoring and } \\ \text { control of pathogenic bacteria in } \\ \text { advanced life support systems: ESA } \\ \text { project focussed on biofilm-formation in } \\ \end{array} \\ & \begin{array}{l}\text { space and microbial detection } \\ \text { ISS }\end{array} \\ \text { XA GJ10 } & \text { Xanthobacter autrophicus GJ10 } \\ \text { NLR } & \text { National Aerospace Laboratory NLR } \\ \text { RPM } & \text { Random positioning machine } \\ \text { OD } & \text { Optical density }\end{array}$

\section{Introduction}

For long duration manned missions such as the International Space Station ISS biotechnological recycling and cleaning processes are promising tools in order to achieve sustainability. For optimal process control of such biotechnological applications knowledge need to be available on the effects space conditions may have on the activity of the microbes used. In addition, by using biotechnological systems in closed environments such as the ISS, hygienic aspects are of significant concern as well. Up till now still little is known on 
the behavior of these bacteria under space conditions inside a spacecraft. Past research gave indications that:

- microbes tend to grow faster and produce more biomass (E. coli, Bacillus subtilis; Klaus et al. 1997; Kacena et al. 1999)

- are able to form biofilms and are able to attach to a large variety of surfaces

- deterioration of materials happens due to microbial activities

- locally high concentration of pathogenic microbes may develop and as such cause bio-hazardous situations.

In 2005 an opportunity came along with ESA's FOTON flight M2 offering a 16 days spaceflight for 39 scientific experiments. For the biological experiment a standard experiment box $(16.4 \times 11.2 \times 14.5 \mathrm{~cm}$, Fig. 1$)$ bolted inside the FOTON capsule became available to BIOCLEAR BV a company based in Groningen, The Netherlands working in the field of environmental and sustainable biotechnology. Since BIOCLEAR required technical support in the field of thermal control and space qualification for this box, The National Aerospace Laboratory, NLR, The Netherlands, became involved in the BIOFILTER project.

For NLR the project was a unique opportunity to design and build an experiment from the start-on and to space qualify the in-house developed biomass sensor.

The BIOFILTER project was a BIOCLEAR initiative in cooperation with international partners: NLR, the University of Groningen, The Netherlands, the University of Milan, Italy and Vermicon $\mathrm{GmbH}$, and incorporated two biological experiments:

1. Biofilm formation and molecular tools under microgravity (ESA-MAP)

2. Microbial growth kinetics under microgravity

Roughly half of the box was available for experiment II, studying microbial growth kinetics, using NLR's sensor equipment. The results of experiment I are not discussed in this paper. For evaluation and interpretation of the experiment II results, understanding of the BIOFILTER equipment and its operation is necessary. The reliability and trustworthy performance of the equipment is critical for the biological interpretation of the results. For more details about the design of the BIOFILTER box and its equipment one is referred to van Benthem et al. (2008) and de Vries et al. (2003).

\section{BIOFILTER Sensor Design}

Accurate determination of bacterial growth curves during spaceflight requires a sensor that is inherently stable, capable of continuous measurements and low power consumption. Work on the biomass sensor started in NLRs laboratory in 1999 (van den Assem et al. 2001; van Benthem et al. 2001) with a trade between two types of optical sensors, both in principle suitable for on-line measurement of bacterial growth. The first method was based on the measurement of light transmission, using a submerged prism, whereas the second method was a turbidity sensor measuring both the transmitted and scattered light. Although the turbidity sensor needed a few improvements to enhance its sensitivity in the low range it had been selected for its features. The sensitivity of the turbidity sensor was significantly improved by implementing logarithmic amplification and using diaphragms to narrow the beams, making it suitable for the application, e.g. online measurement $X$. autrophicus growth (Janssen et al. 1985). The improved turbidity sensor was selected for:

- online measurement of growth

- inherent stability by self compensation

- insensitivity for fouling

- sample volume inside sensor (noninvasive)

- high accuracy (after improvements)

- low power consumption.
Fig. 1 Standard experiment box as available for experiments on FOTON M2
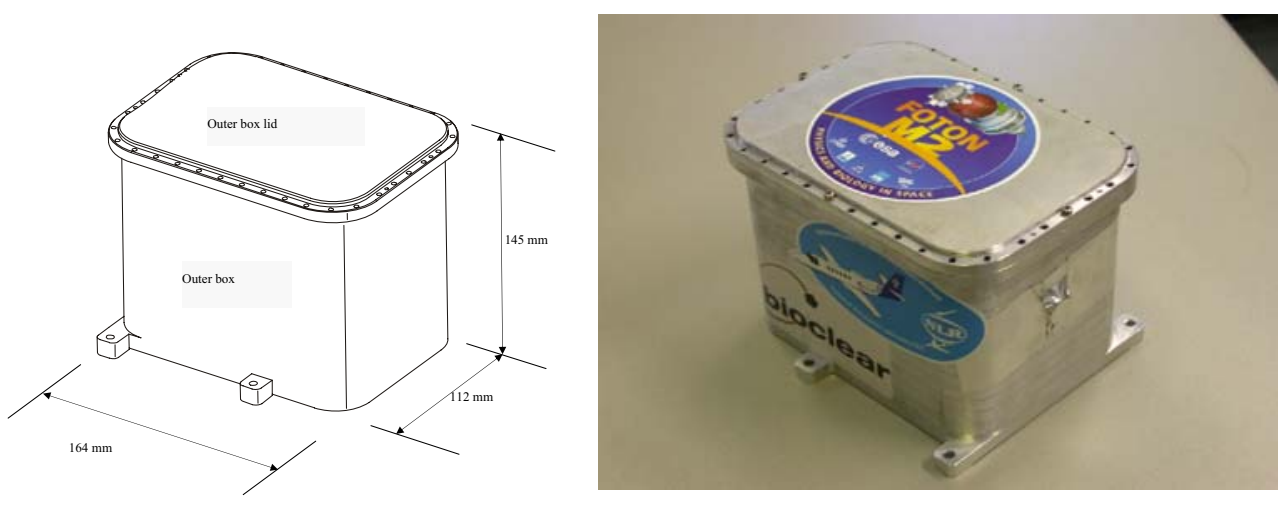


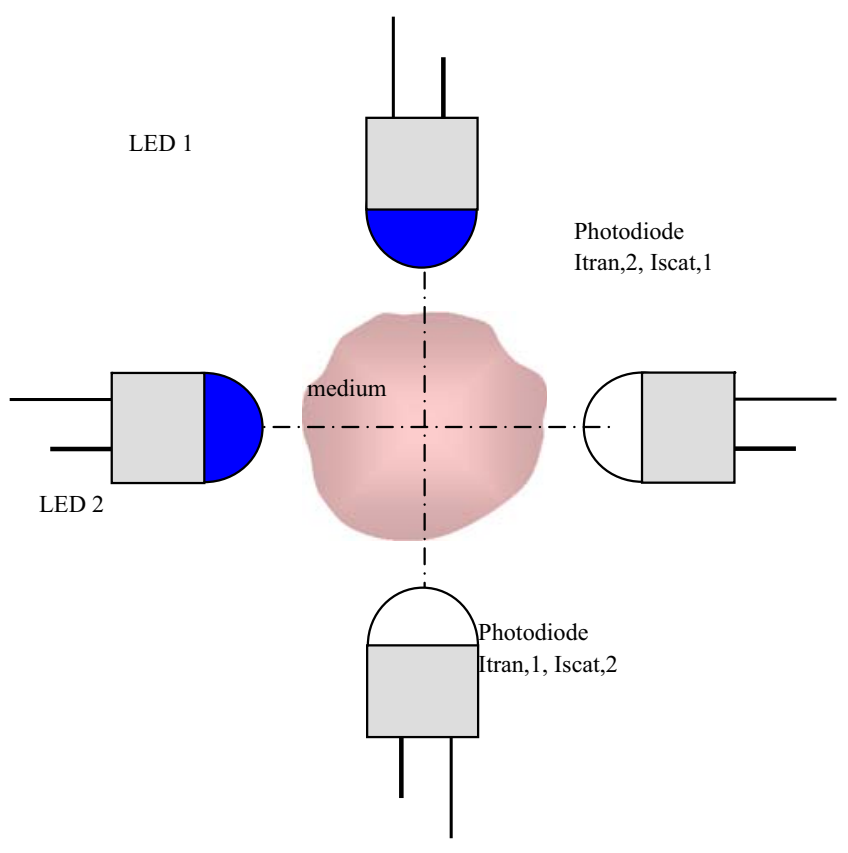

Fig. 2 Turbidity sensor with dual ratio concept as applied in BIOFILTER

The implemented sensor for BIOFILTER is based on dual turbidity measurement, using two LED and two photodiodes arranged in a cross around a medium (Fig. 2). It combines two scatter and transmission measurements. The ratio eliminates LED emission and detector sensitivity fluctuations. Optical properties and geometry of the particles (e.g. bacteria) which produce the turbidity, require appropriate calibration. A blue LED is selected $(\lambda=450 \mathrm{~nm})$, the same wavelength as used in the laboratory to measure the optical density (OD) of $X$. autrophicus with a photo-spectrometer. The geometrical mean value of the alternately obtained ratio values as induced by each light source and detected in real-time. Accordingly, $R$ is calculated online:

$R=\sqrt{\left(I_{\text {scat }, 1} / I_{\text {tran }, 1}\right) \times\left(I_{\text {scat }, 2} / I_{\text {tran }, 2}\right)}$

with:

$R \quad$ dual ratio signal,

$I_{\text {scat } 1}$ scattered intensity signal, induced by LED 1 ,

$I_{\text {tran, } 1}$ transmitted intensity signal, induced by LED 1 , $I_{\text {scat, } 2}$ scattered intensity signal induced by LED 2,

$I_{\text {tran,2 }}$ transmitted intensity signal, induced by LED 2.

The ratio eliminates LED fluctuations and the geometric mean calculation eliminates detector circuit instability and the influence of fouling of surfaces in the optical paths. The detected light energy depends on the wavelength spectrum, the illuminated medium volume, the properties of the suspended particles (optical properties, characteristic dimensions and shape $(X$. autrophicus has a $10 \mu \mathrm{m}$ cylindrical shape) and the suspended particle density (=number of bacteria) For BIOFILTER eight sensors were accommodated in a stack (Fig. 3): seven were used for the measurement of
Fig. 3 BIOFILTER sensor stack

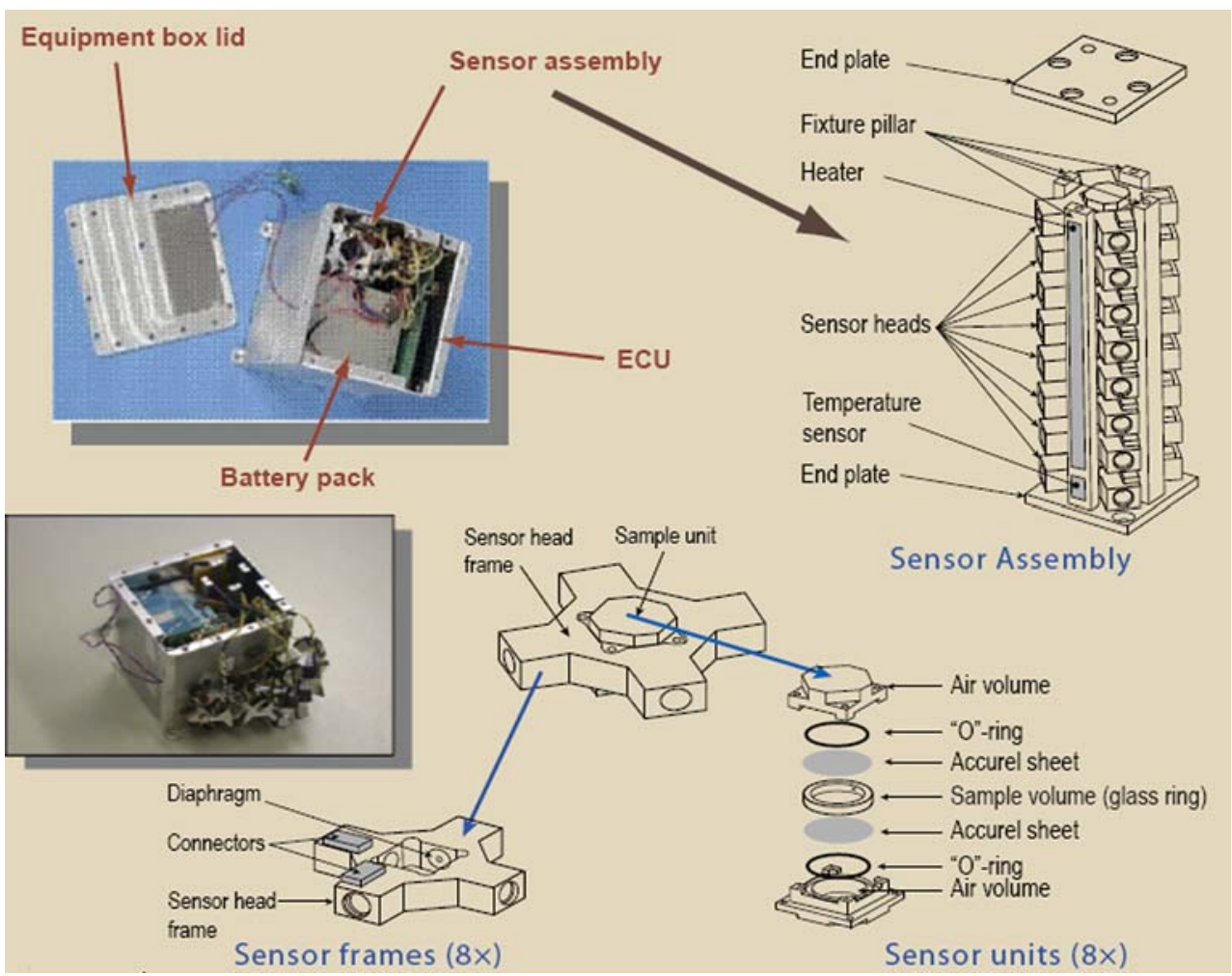


bacteria growth of $X$. autrophicus and one fixed reference. Each sensor has a $2 \mathrm{~mm}$ thick, $1 \mathrm{~cm}$ diameter circular sample unit containing a mineral growth medium with bacteria (inoculum density $5 \% v / v=$ $2.3 \mathrm{E} 7$ cells $/ \mathrm{ml}$ ), in close contact, via Accurel sheets with two air chambers to allow gas exchange. The mineral medium composition was: phosphate buffer; pH7 (4.1 g KH $\left.\mathrm{KO}_{4} / \mathrm{l}\right), 0.2 \mathrm{~g} \mathrm{MgSO}_{4} \cdot 7 \mathrm{H}_{2} \mathrm{O} / 1,0.5 \mathrm{~g}$ $\left(\mathrm{NH}_{4}\right)_{2} \mathrm{SO}_{4} / \mathrm{l}$, demineralised water, $2 \mathrm{ml}$ 'sporen P' solution, which involves: $1.5 \mathrm{mg} \mathrm{Ca}\left(\mathrm{NO}_{3}\right) \cdot 4 \mathrm{H}_{2} \mathrm{O} / 1,0.5 \mathrm{mg}$ $\mathrm{FeSO}_{4} \cdot 7 \mathrm{H}_{2} \mathrm{O} / \mathrm{l}, 25 \mu \mathrm{g} \mathrm{ZnSO} \cdot 7 \mathrm{H}_{2} \mathrm{O} / 1,25 \mu \mathrm{g} \mathrm{H} \mathrm{BO}_{3} / \mathrm{l}$, $25 \mu \mathrm{g} \mathrm{CoCl}_{2} \cdot 6 \mathrm{H}_{2} \mathrm{O} / 1,10 \mu \mathrm{g} \mathrm{MnSO}_{4} \cdot \mathrm{H}_{2} \mathrm{O} / 1,7.5 \mu \mathrm{g}$ $\mathrm{Na}_{2} \mathrm{MoO}_{4} \cdot 2 \mathrm{H}_{2} \mathrm{O} / 1,5 \mu \mathrm{g} \mathrm{NiCl} 2 \cdot 6 \mathrm{H}_{2} \mathrm{O} / \mathrm{l}$. Each sensor has two LEDs and two photodiodes arranged in a cross. One sensor unit is used as a reference using an epoxy with aluminum particles added to achieve a fixed turbidity.

\section{BIOFILTER Flight Results}

\section{Post Flight Inspection}

During post flight inspection when the samples were opened bacterial growth was seen in all seven sensors. Microscopic investigation revealed no changes in the cell morphology. The optical density (OD) of the fluid was vortexed inside the sensors, diluted (to obtain sufficient volume) and measured in the laboratory with a photo spectrometer at the specified wavelength of
$450 \mathrm{~nm}$ for $X$. autrophicus showing the expected level of completed bacterial growth $(\mathrm{OD}=0.47 \pm 0.04)$, the same value as found for the two laboratory reference cultures $(\mathrm{OD}=0.48 \pm 0.02)$. Although not confirmed by microscopic inspection this proves that a film formation on the sensor walls is unlikely, since it is very hard to remove a biofilm by vortexing. The laboratory reference cultures were two bottles with stirred $X$. autrophicus bacteria and medium to proof viability of the bacteria culture.

\section{Sensor Flight Results}

As concluded from the thermal data the actual achieved FOTON M2 temperature profile was close enough to the designed values to ensure bacterial growth in microgravity. The result for FOTON M2 is visible in Fig. 4 taking the averaged of both directions for all sensors, accept for the corrupted sensor 1 and 2 (reference). Some time after launch $(t=330 \mathrm{~h})$ an array of growth curves with growth rates of $0.046-0.077 \mathrm{~h}^{-1}$ up to an $\mathrm{OD}=0.26$ during flight is visible.

As can be seen in Fig. 4 the bacteria growth started in all sensors some time after the switch on of the heater. Directly after switch-off of the heater after 6 days, all curves drop a little, indicating a temporarily growth stop. Two measurements from sensor 4 and 8 show an exceptional long lag-time up to $150 \mathrm{~h}$, both however only measured in one direction, indicating a nonuniform growth and/or distribution of bacteria inside
Fig. 4 FOTON M2 sensor results. OD measurement was derived from the averaged transmission data

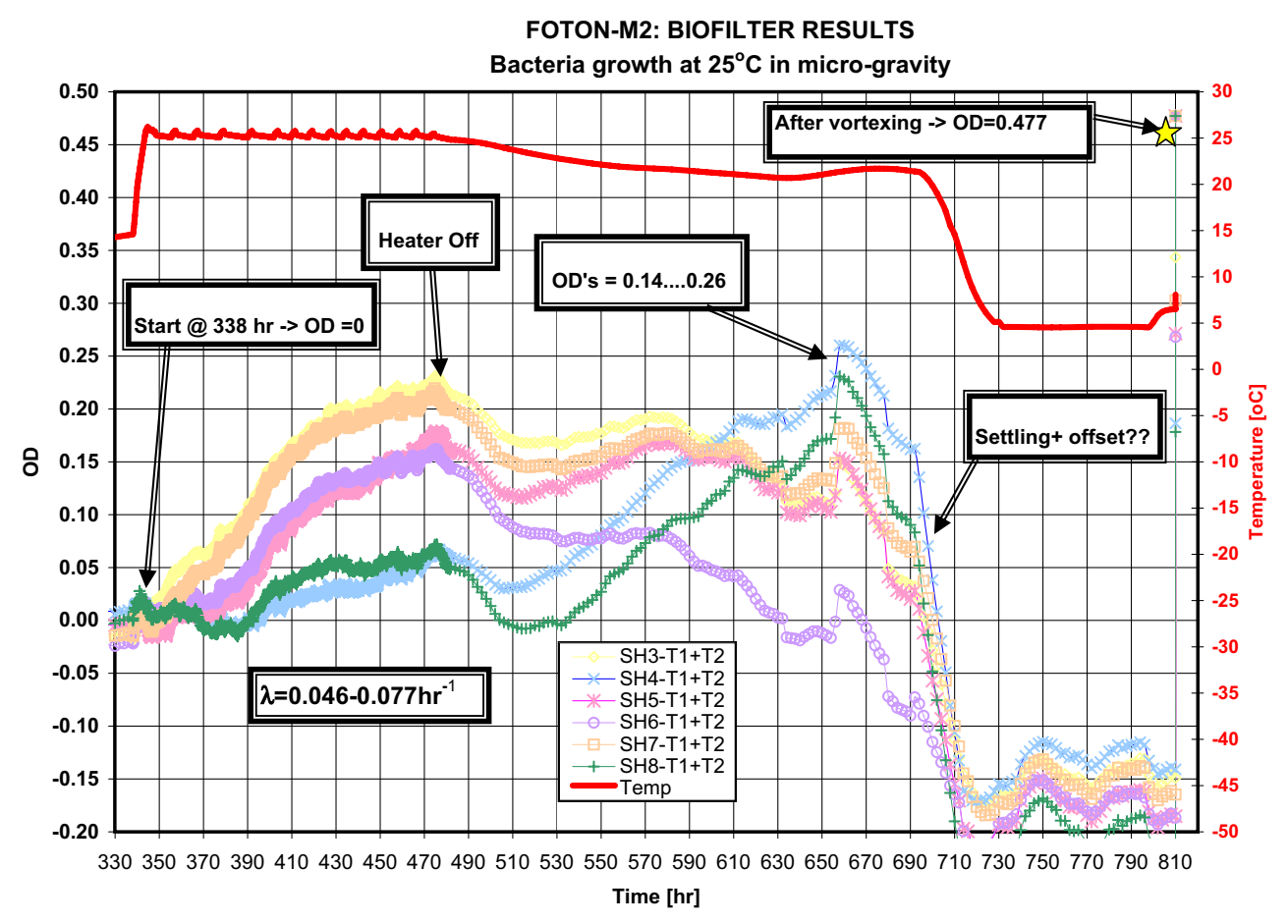


a sensor. In fact a couple of unknown influences that vary in time during the growth making interpretation more difficult. Since in microgravity the fluid in the sensor is most likely not mixed, the measurement signal is incidentally influenced during/after growth by:

- the number of bacteria in the light path

- distribution of the bacteria in the sensor

- temperature

- offsets (unexplained shifts in the measurement signal most likely due to mechanical or electronic related problems).

For OD calibration at the end, all the sensors were vortexed in the laboratory during the post flight inspection, to ensure a uniform distribution of bacterial cells and the highest possible optical density for the fully grown cultures. As confirmed by the raw data the transmission values (maximum OD) after vortexing were the lowest found. Note that during/after reentry and landing, a combined influence of settling of the bacteria under the influence of gravity and an offset indicated by a negative $\mathrm{OD}$ value around -0.15 is visible. However an $\mathrm{OD}=0$ would be normally expected after settling. From previous laboratory experiments performed with this bacteria it is know that settling of the cells occurs at a velocity of about $1.2 \mathrm{~mm} /$ day in static cultures. Since the sensor light beams are approximately $1 \mathrm{~mm}$ across, the bacteria settle within less than $20 \mathrm{~h}$ in the present of gravity. The offset is possibly related to heavy loads during reentry and affects the calibration of the OD levels during the flight, however will not affect the conclusion of a slower growth.

\section{Summary of the Sensor Flight Results}

- post flight inspection revealed bacterial growth in all sensors

- averaged OD $=0.477$ (comparable with the references cultures) found after vortexing in all sensors

- array of growth curves $\left(\mu=0.046-0.077 \mathrm{~h}^{-1}\right)$ after heater switch-on for a temperature between 24$26^{\circ} \mathrm{C}\left(\mu=\ln (2) / t_{\mathrm{d}}, t_{\mathrm{d}}=\right.$ dubbeling time in hours $)$

- indication of non-uniform distribution of bacteria in sensor, possibly by poor fluid mixing in micrograms

- settling after landing under influence of gravity

- offsets occurred during reentry as confirmed by negative $O D$ values after settling

- interpretation difficult due to poor mixing

- indication of slower growth rate's in orbit.

To increase confidence in the equipment, the calibration methods applied and the biological interpretation of the flight results, two ground reference experiments that are discussed in the next sections. The BIOFILTER hardware was placed on a random positioning machine (Van Loon 2007) inside a climate chamber and the flight conditions were repeated as for as possible.

\section{BIOFILTER Ground Reference Experiments}

Introduction

The ground reference experiment was carried out using the BIOFILTER hardware, procedures and replaying the internal temperatures as found during the FOTON M2 mission ensuring that any differences found might be related to the influence of (or absence of) gravity. The objective for the ground reference experiments was to increase confidence in the operation of the sensor technology, in which case the differences in growth (rates) between the flight and ground experiments can be determined. It was anticipated and confirmed by other flight experiments (Klaus et al. 1997; Kacena et al. 1999) that gravity has an effect on the growth of bacteria.

\section{Ground Reference Setup}

Two ground reference experiments using BIOFILTER flight hardware (e.g. the equipment box including the eight sensors) mounted on a desk-top RPM (manufactured and supplied by Dutch Space) The temperature environment is controlled using a coolbox (with heater) - simulating the transport phase-and a climate chamber-replaying the FOTON-M2 internal flight temperature profile. The rotation speed of the RPM is the major difference between the ground experiments. A fast random rotation is applied to simulate $\mu$-gravity conditions and a slow rotation speed is applied to prevent settling of the bacteria to the bottom of the sample cells when exposed to $1 \mathrm{~g}$ conditions. Two ground reference experiments, both lasting 1 month, were carried out:

Og Ground Experiment BIOFILTER equipment box mounted on a fast random rotating RPM $\left(90^{\circ} / \mathrm{min}\right)$ with the intention to simulate $\mu$-gravity conditions.

$1 g$ Ground Experiment BIOFILTER equipment box mounted on slow random rotating RPM $\left(0.5^{\circ} / \mathrm{min}\right)$ with the intention to prevent bacteria settling under normal gravity $(1 g)$ conditions.

As a result of the ground reference experiment it appeared that the names $0 g$ and $1 g$ were not fully 
Fig. $50 g$ Experiment (RPM at $90^{\circ} / \mathrm{min}$ ). Intermediate OD was low due to a poor bacteria culture

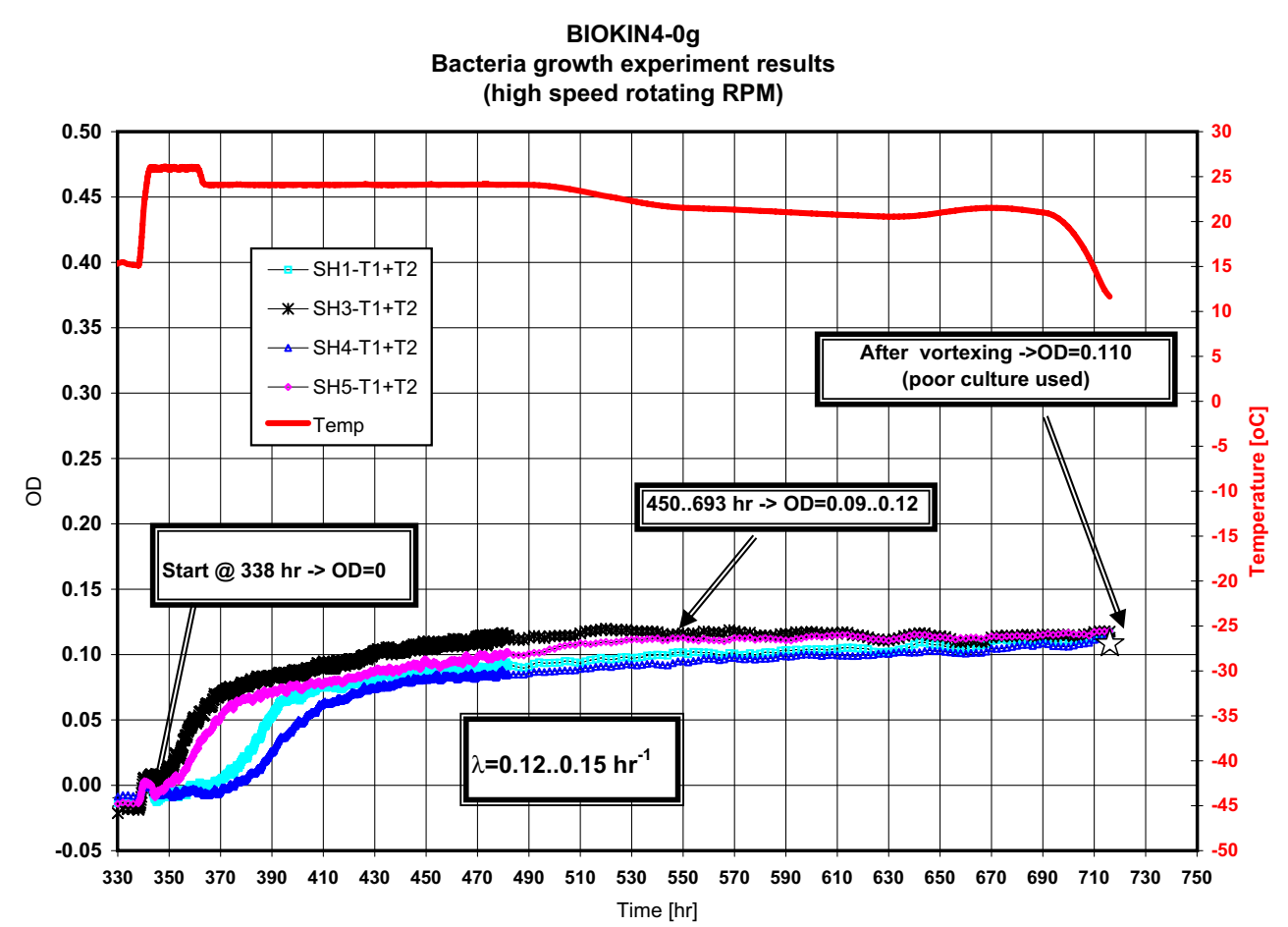

correctly chosen with respect to the simulation of the conditions during flight. For convenience we keep them throughout the paper. For the $0 g$ experiment a rotation speed of $90^{\circ} / \mathrm{min}$ was selected because this was the highest possible rotation speed. Centrifugal forces $4 \mathrm{~cm}$ away from the axis of rotation, roughly were the outer sensors are located were smaller than $0.01 \mathrm{~g}$. For the $1 \mathrm{~g}$ experiment a $0.5^{\circ} / \mathrm{min}\left(=180^{\circ} / 6 \mathrm{~h}\right)$ rotation was selected
Fig. $61 g$ Experiment (RPM at $0.5^{\circ} / \mathrm{min}$ ). Intermediate OD is lower due to poor mixing

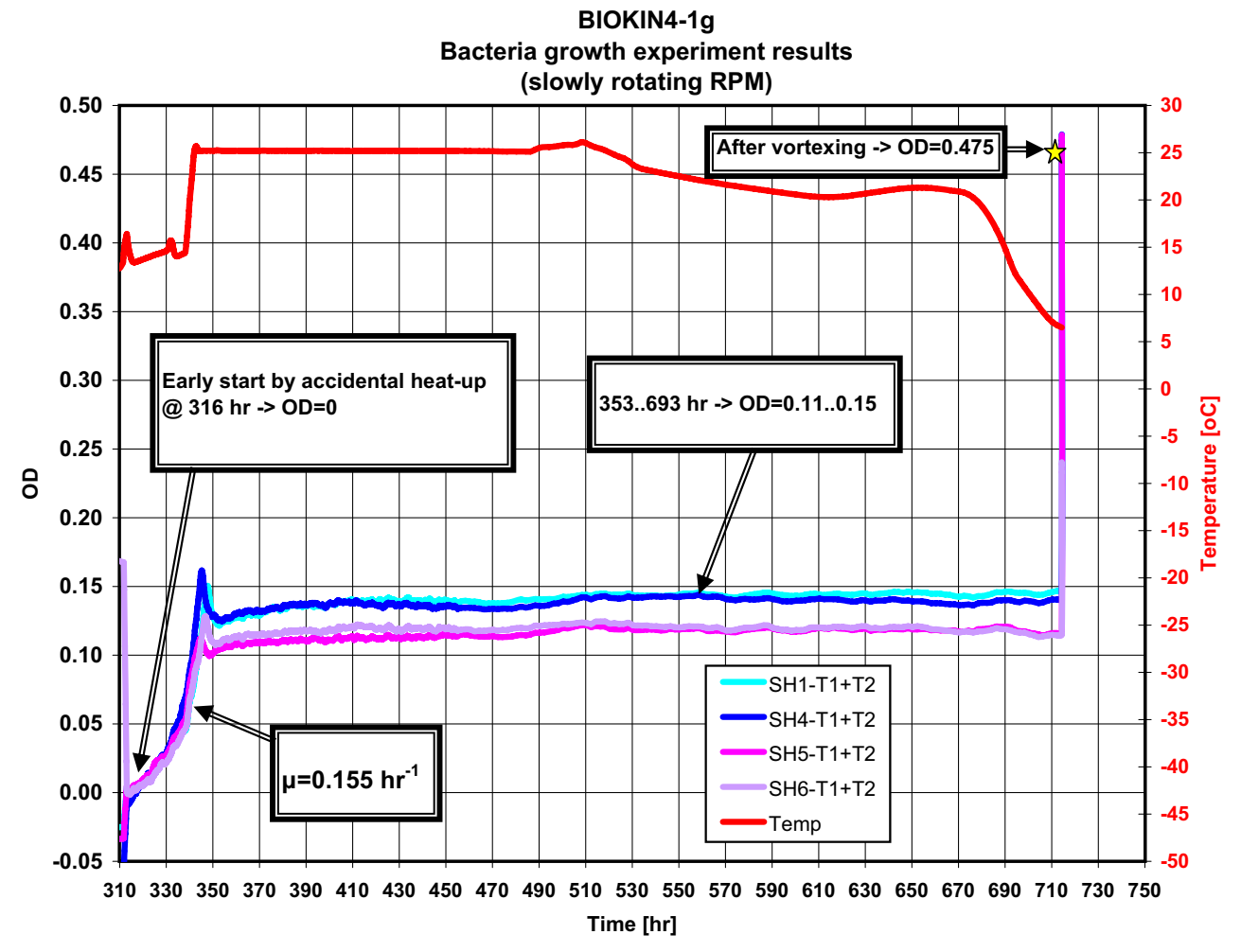


Table 1 Results summary BIOFILTER and ground reference experiments

\begin{tabular}{|c|c|c|c|c|c|c|}
\hline $\begin{array}{l}\text { Experiment } \\
\text { at } 24-25^{\circ} \mathrm{C} \\
\end{array}$ & $\begin{array}{l}\text { Laboratory refer- } \\
\text { ence culture OD }\end{array}$ & Conditions & $\begin{array}{l}\text { Intermediate OD } \\
\text { (end off 'flight' phase) }\end{array}$ & $\begin{array}{l}\text { Final OD } \\
\text { (after vortexing) }\end{array}$ & $\begin{array}{l}\text { Doubling } \\
\text { time } t_{\mathrm{d}}(\mathrm{h}) \\
\end{array}$ & $\begin{array}{l}\text { Growth rates } \\
\mu=\ln (2) / t_{\mathrm{d}}\left(\mathrm{h}^{-1}\right)\end{array}$ \\
\hline $\begin{array}{l}\text { FOTON-M2 } \\
0 g \text { ground }\end{array}$ & $0.48 \pm 0.02$ & ce flight) & $0.05-0.45$ & $0.477 \pm 0.04$ & $9-15$ & $0.046-0.077$ \\
\hline $\begin{array}{l}\text { experiment } \\
1 g \text { ground }\end{array}$ & $0.109 \pm 0.015^{\mathrm{a}}$ & $\Omega_{\mathrm{RPM}}=90^{\circ} / \mathrm{min}$ & $0.11 \pm 0.01$ & $0.11 \pm 0.01$ & $4.5-6$ & $0.115-0.154$ \\
\hline experiment & $0.39 \pm 0.02$ & $\Omega_{\mathrm{RPM}}=0.5^{\circ} / \mathrm{min}$ & $0.12 \pm 0.02^{\mathrm{b}}$ & $0.475 \pm 0.06$ & 6 & 0.115 \\
\hline
\end{tabular}

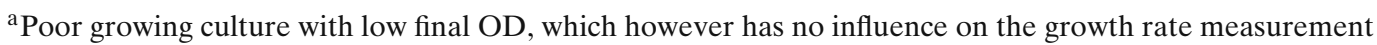

${ }^{\mathrm{b}}$ The lower intermediate OD—with respect to the final OD of the $1 g$ experiment-is most likely related to poor mixing due to the slow rotation of the RPM

to compensate for bacteria settling effectively turning the $2 \mathrm{~mm}$ cells upside-down four-times-a-day.

\section{Ground Experiments Results}

The environmental conditions for both $0 g$ and $1 g$ experiments were correctly carried out, simulating the internal BIOFILTER temperature within $\pm 1^{\circ} \mathrm{C}$ throughout the significant periods.

\section{Og Experiment Results}

Sometime after start-up of the $0 g$ experiment (with the RPM rotation at $90 \% \mathrm{~min}$ ) it appeared that the bacteria culture used was not growing as expected. Both the parallel references cultures showed poor growth to an OD of $0.109 \pm 0.015$ whereas an OD between $0.4-0.5$ is expected. The poor growth of the applied culture was also confirmed by the low final OD as extracted from the sensors, after completion of the $0 g$ experiment.

Although the growth was poor and the sensor signals were noisy it was possible to evaluate the results. In Fig. 5 the results of the $0 g$ experiment are plotted after OD calibration. Sensor 1, 3,4 and 5 are selected giving the best results. Interesting is that the final OD mea-

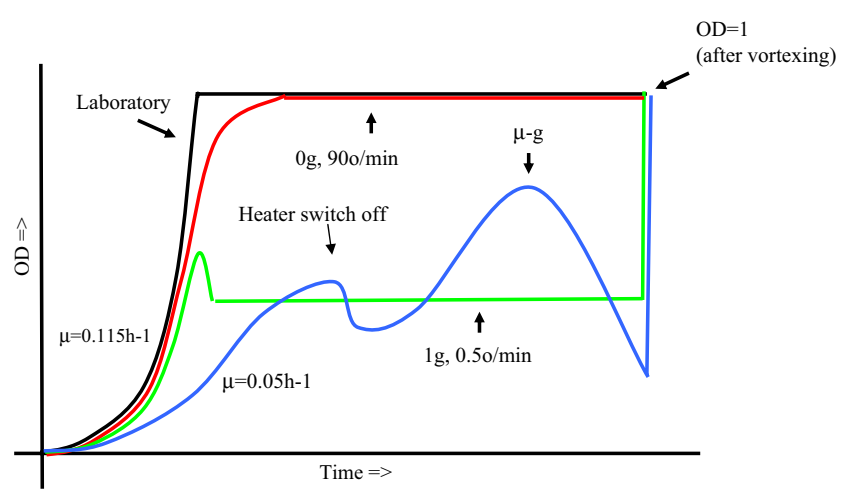

Fig. 7 Normalized picture of the BIOFILTER flight and ground reference sensor test results sured after vortexing showed no difference with the end value obtained during the $0 g$-ground experiment. This indicates that the fast rotation of the RPM ensured uniform distribution of the bacteria during the experiment. Doubling times $\left(t_{\mathrm{d}}\right)$ were found between 4.5 and $6 \mathrm{~h}$ e.g. 'normal' growth rates at $26^{\circ} \mathrm{C}$, resembling growth rates in the range of between $\mu=0.12-0.15 \mathrm{~h}^{-1}$. The growth spreading is most likely related to the poor and noisy signal (low OD) and a $1{ }^{\circ} \mathrm{C}$ lower environmental temperature for some of the delayed growing cultures (sensor 1 and 4). Note that no offsets occurred this time.

\section{$1 g$ Experiment Results}

For the $1 g$ experiment the reference cultures showed a final OD of $0.39 \pm 0.02$. The averaged OD measured after the $1 g$-experiment (vortexed, extracted and diluted from the samples) revealed a slightly higher value $\mathrm{OD}=0.475 \pm 0.06$. This value is used for the calibration of the sensors. From Fig. 6 the averaged OD during the experiment was found between 0.11 and 0.15 , significantly lower than measured after vortexing, indicating that due to the slow rotation of the RPM the bacteria partially settled outside the range of the optical beams. After temperature stabilization, a doubling time of approximately $6 \mathrm{~h}$ is measured, indicating a normal growth rate of $\mu=0.12 \mathrm{~h}^{-1}$.

\section{Ground Reference Experiments Results Summary}

In Table 1 the results of both the ground experiments are summarize and compared with the BIOFILTER results. To give an overview of the results in a graphical form in Fig. 7 where the laboratory (van den Assem et al. 2001; van Benthem et al. 2001), BIOFILTER and ground reference results are normalized to an $\mathrm{OD}=1$ and schematically plotted.

Interpretation should take into account sensor limitations and physical influences such as poor mixing and non-uniform bacterial distribution in $\mu \mathrm{g}$ and rotational speeds of the RPM. 


\section{Conclusions}

The BIOFILTER experiment on board FOTON offered a platform to study the effects of microgravity on microbial growth kinetics, though the measurement is compromised by poor mixing of the bacteria. The BIOFILTER project was a unique opportunity to design; build and test a space qualify the in-house developed turbidity sensor subsystem. The bacterial growth, trigged by a heater, started nicely in orbit. The performance of the sensor subsystem was degraded by malfunction of the electronics. A work-around was found, revealing an array of growth curves and slower growth rates in flight. Biological interpretation is compromised by unknown phenomena such as biofilm formation, sensor instabilities, poor mixing and non-uniform distribution of the bacteria in microgravity. Sensor offsets, most likely related to re-entry, has only an influence on the OD level and not on the measured (slower) growth rate. To increase confidence in the equipment and the flight results, two ground reference experiments were performed, using BIOFILTER hardware. Both ground experiments show a nice growth curve at least indicating a correct functioning of the equipment and methods applied. The $1 g$ experiment (slow rotation RPM) proved that mixing is necessary to see the full bacterial growth. The $0 g$ experiment (fast rotation RPM) shows precisely the same growth rate as found under laboratory conditions on earth. Does this mean that the growth rate is not influenced by (simulated) microgravity or that the RPM does not fully simulates reduced gravity conditions? Clearly bacterial growth measurements under these conditions (poor mixing) in a fluid are not ideal. These questions need to be addressed for further flight experiments on bacterial growth kinetics using comparable systems.

Acknowledgements We like thank all the people that were involved during the eight years needed for the BIOFILTER project. Michel Brouwer, former head of NLRs Space Department for his ongoing support in difficult times. Henk Leeuwis, Albert Prak (Lionix BV) for the use of their turbidity sensor at the start of our research program.. Ton Casteleijn for implementation of the logarithmic amplification, Deen van de Assem, for management of the FOTON M1 project. Antoine de Vries and Gerrit van Donk for their contribution to the thermal design. Guus Borst (Dutch Space BV) for the use of the RPM for the ground reference experiments and Rene Demets (ESA) for technical support on site in Baikonur. This research received financial support by the Netherlands Agency for Aerospace Programmes.

Open Access This article is distributed under the terms of the Creative Commons Attribution Noncommercial License which permits any noncommercial use, distribution, and reproduction in any medium, provided the original author(s) and source are credited.

\section{References}

de Vries, A., van Es, J., de Grave, W., van den Assem, D.: Thermal insulation of autonomous experiment containers in pressurized environments during pre-launch installation. Conference paper. 03ICES-72 (2003)

Janssen, D.B., Scheper, A., et al.: Degradation of halogenated aliphatic compounds by Xanthobacter autotrophicus GJ10. Appl. Environ. Microbiol. 49(3), 673-677 (1985) (Mar)

Kacena, M.A., Merrell, G.A., Manfredi, B., Smith, E.E., Klaus, D.M., Todd, P.: Bacterial growth in space flight: logistic growth curve parameters for Escherichia coli and Bacillus subtilis. Conference paper. Appl. Microbiol. Biotechnol. 51, 229-234 (1999)

Klaus, D., Simske, S., Todd, P., Stodiek, L.: Investigation of spaceflight effects on Escherichia coli and a proposed model of underlying physical mechanisms. Conference paper. Microbiology. 143, 449-455 (1997)

van Benthem, R., van den Assem, D., Kroonenman, J.: Compact optical sensor for real-time monitoring of bacterial growth for space applications. In: UEF Proceedings Micro-gravity Transport Processes in Fluid. Thermal, Biological and Material Sciences II, Banff, Canada (2001)

van Benthem, R.C., Krooneman, J., de Grave, W., HamingaDorenbos, H.: Thermal design and turbidity sensor for autonomous bacterial growth measurements in space-flight. Conference paper. New York Academy of Sciences Annals 1426-054 (2008)

van den Assem, D., van Benthem, R., Casteleijn, A.: Self compensating real-time biomass sensor. ESA conference publication. In: Proceeding of the First International Symposium on Micro-gravity Research and Applications in Physical Sciences and Biotechnology, Sorrento, Italy, 10-15 September 2000, ESA SP-454 vol. 1, pp. 1053-1059 (2001)

Van Loon, J.J.W.A.: Some history and use of the random positioning machine, RPM, in gravity related research. Adv. Space Res. 39, 1161-1165 (2007) 